\title{
Functional analysis of scapular position in assymptomatic professors
}

\author{
Geraldo Fabiano de Souza Moraes ${ }^{\mathrm{a},{ }^{*}}$ and Davidson Passos Mendes ${ }^{\mathrm{a}}$ \\ ${ }^{a}$ University Federal of Itajubá - Campus Itabira, Rua Um $s / n^{\circ}$ Distrito Industrial. Itabira. Minas Gerais. Brasil. \\ CEP 35903-081.
}

\begin{abstract}
The impaired performance of the muscles of the scapular region may result in injuries, fatigue, weakness and pain. The main objective of this research was to analyze the scapular positioning during the abduction of the shoulder movement in the frontal, scapular and sagittal plans. Method: This cross-sectional study comprised a convenience sample of 20 individuals. It was used the disability of the arm, shoulder and hand questionnaire (DASH Brazil), the digital inclinometer was used for measuring the scapular positioning. Having the purpose of regulating and ensuring the correct positioning of the upper limbs Assessed in the plans, it was developed the bulkhead which was used while the examination was performed. Results: The population study was asymptomatic. No significant difference was found for the right shoulder during the concentric and eccentric contraction at all angles of scapular inclination on the three analyzed plans. Significant difference was found in the left shoulder during the concentric contraction in the scapular angle at $90^{\circ}$ and in the eccentric contraction at the scapular angles of $30^{\circ}, 60^{\circ}$ and $90^{\circ}$ of inclination in the frontal plan compared to men and women. Furthermore, it was found a decreasing left shoulder in the scapular angle during the eccentric contraction above $90^{\circ}$ in the scapular and sagittal plans when compared to men and women. Conclusion: we concluded that in the three plans studied, the scapula behaved differently various angles in the measured and yet it was influenced by the direction of motion. Moreover, it is possible to say that showed that this study there is a difference in the rotational behavior of the scapula relating to women and men due to the anthropometric existed differences between them.
\end{abstract}

Keywords: ergonomics, occupational risk, scapular position, biomechanics

\section{Introduction}

Atypical position of the shoulder blades adversely affect the position of the shoulder joint, and joint misalignment that may predispose to injury and chronic pain $[1,2,3]$. Changes in the complex of the shoulder and scapular girdle are common and often merit attention in the physical therapy evaluation [1.3].

The move allows the scapular articular surface of the glenoid cavity becomes relatively centered on the joint surface in contact with the humeral head, an essential factor for maintaining the stability of the shoulder joint complex [4.5]. The scapula has a highly mobile and has a close relationship with the glenohumeral joint during motion analysis of upper limb, determines the so-called scapulohumeral rhythm [5.6].
The performance can result in compromised muscle microdamage, muscle strain, neurological damage, fatigue, weakness and pain. There are several musculoskeletal disorders in the literature due to the unusual movement of the upper limbs (UL), the most prevalent are rotator cuff tendinosis, lateral epicondylitis, tenosynovitis or paratendinite wrist or forearm and carpal tunnel syndrome [7].

Thus, the proper movement of the scapula, which allows the muscles that move the humerus have an effective length-tension relationship over the proper range of motion (ROM), and help maintain a good congruence between the glenoid cavity and the head of humerus, which decreases the shear strength of joint $[4,8,9]$.

Some authors have suggested that the occurrence of unusual scapular motion, by way of compensation to the detriment of functionality during a WMD, can

\footnotetext{
"Corresponding authors. E-mail: geraldmoraes@terra.com.br
} E-mail: davidsonpmendes@gmail.com 
lead to subacromial impingement and glenohumeral instability, and postural disorders $[5,10,11]$.

Currently, there is great concern with preventing a variety of diseases and injuries involving the shoulder joint due to postural changes that lead to the compensation system over the feature [12].

The prevalence of shoulder pain accompanied by disability is present in about $20 \%$ in the general population [13]. The situations that overload in this joint complex are multifactorial, such as large repetitive movements, static posture and movements inadequate, muscle imbalances, position of UL, especially in abduction, muscle fatigue, insufficient time for tissue repair factors; of work organization and cancellation of regulatory mechanisms, such as overload (folds of shifts, decrease or lack of range) and psychosocial factors that lead to tension and stress [7].

This work has become of great importance with regard to the need to analyze the positioning of the scapula in the plans frontal, sagittal and scapular and the results will serve as support for prevention of disorders of the shoulder complex to the action of physiotherapy, as well as providing reliable evidence of the evolution of these individuals and the need for maintenance or change therapy. Therefore, the purpose of this study was to analyze the scapular positioning in the abduction movement of the shoulders in frontal, scapular and sagittal.

\section{Methodology}

\subsection{Study design and sample}

This cross-sectional study comprised a convenience sample of 20 individuals, 10 men and 10 women, and the study was conducted at the Laboratory of Kinesitherapy Faculty of Health Sciences - University Center Newton Paiva. To participate in this study they were asked to fill out the following inclusion criteria: aged between 25 and 40, any genre, no complaint of shoulder pain and be university professors at least a year. We excluded those who were in physical therapy, underwent surgery on upper limbs, possessed any change that would preclude completion of the procedures, had diabetes, uncontrolled hypertension or heart disease. This project was approved by the Ethics Committee in Research of Newton Paiva University Center in the opinion No. 136 on May 20, 2010.

\subsection{Instruments}

\subsubsection{Dash Brazil}

It was used the Questionnaire of Disability of the Arm, Shoulder and Hand (DASH Brazil), culturally adapted to Portuguese in Brazil by Orfalea et al. [14]. It was proposed to evaluate disability and symptoms in a single or multiple disorders of the upper [14].

\subsubsection{Digital inclinometer}

The Inclinometer Digital Protractor Mitutoyo (Mitutoyo (C) Evaluation Instruments, Aurora, Chicago, IL) was used for measurement of scapular positioning. Two extension arms have been adapted $(10 \mathrm{~cm}$ each), made of acrylic, for proper accommodation of the equipment in the reading of the scapula and degrees of tilt. It was engaged at a level of water perpendicular to the equipment, to ensure correct alignment of the same for the evaluation plans.

The digital inclinometer can measure angles up to $360^{\circ}$ with an accuracy of $0.1^{\circ}$, as reported in the manufacturer's manual. The validity and reliability of using the digital inclinometer, as a way of measuring scapular position was described by Johnson et al. (15). It was used 39 individuals, 16 affected and 23 with shoulders with no involvement. Reliability was assessed using repeated measures with equipment from two different comparisons: one using a digital inclinometer and a magnetic device for threedimensional measurements. The results of the correlation coefficient (ICC) ranged from 0.89 to 0.96 . Pearson's coefficient was used to determine the validity of digital inclinometer ranged from $r=0.74$ to 0.92 , compared to the static magnetic device for three-dimensional measurements, and ranged from $r$ $=0.59$ to 0.73 , when compared to the magnetic device active for three-dimensional measurements.

\subsection{Procedures}

To standardize and ensure the correct positioning of the upper limbs was assessed plans developed in a screen used during the execution of the test. The screen simulator planes of movement of the arms had two tabs indicating the angles of $0^{\circ}$ to $180^{\circ}$, separated by $10^{\circ}$ in 10 . The tabs of the shield could move and be fixed in the frontal, scapular and sagittal. Moreover, the tabs on the screen could also move up, down and sideways to fit the height and width of the shoulders of the volunteers.

Initially, all volunteers were instructed about the objectives and procedures of the study and signed an informed consent. They were then sent to a personal interview by trained evaluators to collect demograph- 
ic data and the application of the DASH questionnaire in Brazil and the data were stored for later analysis. Later, the volunteers were sent to other procedures.

The volunteers were positioned standing upright in the simulator screen, which was then duly adapted to the height and width of the individual and placed first with their legs in the frontal plane. One appraiser, properly trained, placed the digital inclinometer on the spine of the scapula through the arms adapted to the equipment for proper placement and accommodation of the indicated anatomical reference, the spine of the scapula and the edge medial and inferior of the acromion. A second evaluator to read and record the values observed in the resting position of the MS (anatomical position), $30^{\circ}, 60^{\circ}, 90^{\circ}, 120^{\circ}$ and $180^{\circ}$ of shoulder elevation in the frontal plane in the ascent and descent. The same measures were performed in the scapular and sagittal planes.

\section{Statistical Analysis}

The analysis was descriptive of the demographics and history for all volunteers. We used the Student $t$ test for independent samples to compare means of groups in relation to the scapular positioning.

\section{Results}

\subsection{Sample characterization}

The study included 20 volunteers, ten women and ten men, aged between 27 and 37 years and all university professors. The amount of hours / week school conducted ranged from seven to 60 hours. The 20 participants were evaluated both shoulders (40 shoulders). Table 1 presents data describing the demographic characteristics and history of the groups.
Table 1

Demographic characteristics and history of the samples investigated

\begin{tabular}{|c|c|c|c|c|}
\hline Gender & $\begin{array}{l}\text { Average } \\
\text { Age } \\
\text { (min - } \\
\max )\end{array}$ & Dominance & $\begin{array}{c}\text { Average } \\
\text { hours } \\
\text { worked per } \\
\text { week (min- } \\
\text { max) }\end{array}$ & $\begin{array}{c}\text { Physical Activ- } \\
\text { ity }\end{array}$ \\
\hline $\begin{array}{c}\text { Female } \\
(n=10)\end{array}$ & $\begin{array}{c}31,3 \\
\text { years } \\
(28-36)\end{array}$ & $\begin{array}{l}9 \text { right e } \\
1 \text { left }\end{array}$ & $\begin{array}{c}33,0 \text { hours } \\
(10-47)\end{array}$ & $\begin{array}{c}4 \text { active e } \\
6 \text { sedentary }\end{array}$ \\
\hline $\begin{array}{l}\text { Male } \\
(\mathrm{n}=10)\end{array}$ & $\begin{array}{c}31,8 \\
\text { years } \\
(27-37)\end{array}$ & $\begin{array}{l}8 \text { right e } \\
2 \text { left }\end{array}$ & $\begin{array}{c}30,8 \text { hours } \\
(07-60)\end{array}$ & $\begin{array}{l}3 \text { active e } \\
7 \text { sedentary }\end{array}$ \\
\hline
\end{tabular}

\subsection{Variables analyzed}

\subsubsection{Analysis of the DASH Brazil}

The average of the first thirty issues of DASH in Brazil for women was 1.67 (from 0 to 8.33 points) and fourth options, work-related was 0.62 (from 0 to 6.25 points). The average of the first thirty issues of DASH Brazil, for men was 1.17 (from 0 to 5.83 points) and four work-related options was 0 . Thus, with the DASH score of Brazil in the group of women and men, we conclude that all the patients studied were asymptomatic.

\subsubsection{Scapular inclination angle}

No significant difference was found for the D shoulder during the concentric contraction at all angles of scapular inclination on the three planes analyzed ( $p>0.05,0.06<p<0.89$ ). No significant difference was found for shoulder D during eccentric contraction in all scapular tilt angles in the three planes analyzed ( $p>0.05,0.07<\mathrm{p}<0.97$ ). Was a significant difference to the shoulder during the concentric contraction and the scapular inclination angle $90^{\circ}(\mathrm{p}=$ 0.03 ) in the frontal plane compared to women than to men.

There was significant difference in the shoulder during the eccentric contraction and in the scapular inclination angles $30^{\circ}(\mathrm{p}=0.04), 60(\mathrm{p}=0.01)$ and $90(\mathrm{p}=0.02)$ in the frontal plane by comparing the women compared to men. In addition, we found a decrease of the inclination angle on the shoulder and scapula during eccentric contraction above $90^{\circ}$ in the scapular and sagittal planes compared to women than to men. 


\section{Discussion}

The results demonstrated in the group of men a rotation greater the scapula in the scapular plane than in the sagittal plane during the concentric contraction and eccentric right shoulder and during the concentric contraction of the shoulder and the bow end of the high humeral $\left(90^{\circ}\right.$ to $\left.180^{\circ}\right)$. During the eccentric contraction of the shoulder in males and only 180 degrees there was a greater rotation of the scapula in the scapular plane than in the sagittal plane. In relation to the group of women, there was a greater rotation of the scapula in the scapular plane than in the sagittal plane during eccentric contraction of the right shoulder in the final arc of humeral elevation $\left(90^{\circ}\right.$ to $\left.180^{\circ}\right)$.

During the concentric and eccentric contraction of the shoulder and the group of women was only $180^{\circ}$ rotation of the scapula greater in the scapular plane than in the sagittal plane and on the right shoulder during the concentric contraction that occurred from $120^{\circ}$. In both groups found a greater scapular rotation in the frontal plane than other planes at all angles.

In a study by Borsa et al. [11] demonstrated a similar result where there was an upward rotation most of the scapula in the scapular plane than in the sagittal plane during the final arc of high humeral $(90$ ${ }^{\circ}$ to $\left.120^{\circ}\right)$, and these authors did not evaluate the angle of 180 degrees and also did not evaluate the frontal plane.

It can infer that the lower scapular rotation in the sagittal plane is due to the limited removal subacromial humeral head during elevation of the humerus. This difference in elevation between the humeral plans during the terminal stage of scapular rotation is an important finding when considering the relationship between the rotation and scapular subacromial shock.

During the evaluation of a patient with an affected shoulder, scapular rotation seen in the sagittal and scapular can be useful to observe the dyskinetic scapular motion. Our findings suggest that to decrease the chances of subacromial shock, may be more beneficial for patients with tendinopathy rehabilitation run air exercises in the scapular plane than in the sagittal plane.

In our study we found a significant difference to the shoulder during the concentric contraction and the angle of the scapula $90(\mathrm{p}=0.03)$ in the frontal plane compared to women than to men.

According Sahrmann [16], the exact chronology of the movement of the scapula would be subject to a certain degree of variability. Therefore, in clinical practice, when analyzing patients who report pain and to compare one to the other shoulder, the examiner can obtain a reference point that can guide your decision on whether the case is dysfunction of movement or just a variation normal. The observation of deviations from the timing and range of motion of the scapula in combination with the timing of the onset of pain and to identify changes in muscle performance, is another measure that can guide the decision on the significance of deviations found.

In his professional practice, teachers constantly change their positions depending on the task to be executed. The effectiveness of task execution can be reflected in postural adjustments adopted by the apparatus and the ability of individual settings of the same [17-21].

Klous et al. [22] concluded that the preparation for a disruption self-harm is associated with postural adjustment synergistic anticipatory postural adjustments and anticipatory. These reflect different processes in hypothetical hierarchical control scheme, resulting in changes in patterns of covariation of key issues and their standards. They showed in their study, which quantified synergies, joint muscles using different associations, show similar changes in preparation for action to be executed.

The large breasts favor the abduction of the scapula because the increased size of the chest requires the individual to abduct the shoulder blades, to increase the excursion of the arms in front of the body [16].

Obtained as a result a significant difference to the shoulder and during eccentric contraction in the scapular inclination angles $30^{\circ}(\mathrm{p}=0.04), 60(\mathrm{p}=0.01)$ and $90(\mathrm{p}=0.02)$ in the frontal plane compared to women than to men. We can infer that this difference may be due to the volume of the breasts in women, because $90 \%$ of them having a dominant right hand, his left side would have a lower activity and thus happen in scapular motion compensation which would lead to this difference in the angle of inclination scapula during eccentric contraction in the shoulder and reinforced with a postural change due to gravity, the mass of the body segment and muscle action during the return movement of abduction.

Findikcioglu et al. [23], in a study comparing women with breast volumes of different sizes, no significant differences in increased thoracic kyphosis $(\mathrm{p}=0.023)$ and lumbar lordosis $(\mathrm{p}=0.045)$ comparing the subjects in the group with the highest volume of the breasts with the group lower volume. There was also an increase in lumbar lordosis compared 
with a second volume of a breast with the intermediate of larger volume $(\mathrm{p}=0.008)$.

Working conditions, or circumstances under which teachers mobilize their physical, cognitive and affective to achieve production objectives school can lead to overexertion or overload in their psychophysiological functions. If no time for recovery, are triggered or precipitate clinical symptoms that explain the levels of absenteeism work for physical disorders.

The accumulation of knowledge in the field study of the relationship of health and work permits assumed associations between poor health identified in the category of teachers and ergonomic conditions of work.

In this context, observe an increased frequency of occupational diseases and accidents at work, where the teacher is the victim. Based on these considerations, it is necessary to an understanding of work organization and its disastrous consequences to the health teacher, your working environment brings to them.

Thus, further studies should be thinking in correlation by using anthropometric measurements, muscle activity and scapular positioning, possible correlations during movements of the shoulder joint complex in different planes of movement., as well as know these relations in mental and cognitive level.

\section{Conclusion}

In the three plans studied the scapula of professors asymptomatic behaves differently in different angles and also evaluated influenced the direction of motion. Moreover, it is possible to conclude that there is a difference in the rotational behavior of the scapula relating to women and men due to the anthropometric measures between them and the accommodation and postural adaptations and muscle specificity by the use of upper limbs in diverse activities performed by teachers.

\section{References}

[1] C.D.C.M Faria, L.F. Teixeira-Salmela, F.R.P. Goulart, G.F.S Moraes, Scapular Muscular Activity With Shoulder Impingement Syndrome During Lowering of the Arms, Clinical Journal of Sport Medicine, 18 (2008), 130-136.

[2] B.E. Heyworth and R.J. Williams III, Internal impingement of the shoulder, American Journal of Sports Medicine, 37 (2009), 1024-1037.

[3] S.B. Behrens, J. Compas, M.E. Deren and M. Drakos, Internal impingement: a review on a common cause of shoulder pain in throwers, Physician Sportsmed, 38 (2010), 11-18.
[4] K.J. Mcquade, S.H. Wei and G.L. Smidt, Effects of local muscle fatigue on three-dimensional scapulohumeral rhythm. Clinical Biomechanics, 10 (1995), 144-148.

[5] R. Matias, A.G. Pascoal, The unstable shoulder in arm elevation: A three-dimensional and electromyographic study in subjects with glenohumeral instability, Clinical Biomechanics, 21 (2006), 25-58.

[6] W.M. Weiser, T.Q. Lee, W.C. Mcmaster and P.J. Mcmahon, Effects of simulated scapular protraction on anterior glenohumeral stability, American Journal of Sports Medicine, 27 (1999), 801-5.

[7] J.N. Côté, D. Raymond, P.A. Mathieu, A.G. Feldman, M.F Levin, Diferences in multi-joint kinematic patterns of repetitive hammering in healthy, fatigued and shoulder-injured individuals, Clinical Biomechanics, 20 (2005), 581-590.

[8] S.T.M. Soares, Trabalho preventivo para lesões de ombro e cintura escapular em atletas amadores de judô. Revista Brasileira de Ciência e Movimento, 11(2003), 29-34.

[9] J.H. Groot, E.R. Valstar and H.J. Arwert. Velocity effects on the scapulo-humeral rhythm, Clinical Biomechanics, 13 (1998), 593-602.

[10]A.R. Karduna, P.J. Kerner and M.D. Lazarus, Contact forces in the subacromial space: Effects of scapular orientation, Journal of Shoulder and Elbow Surgery, 14 (2005), 393-399.

[11]P.A. Borsa, M.K. Timmons and E.L. Sauers, Scapularpositioning patterns during humeral elevation in unimpaired shoulders, Journal of Athletic Training, 38 (2003), 12-17.

[12] G.F.S. Moraes, L.F. Teixeira-Salmela, C.D.C.M. Faria, Scapular muscle recruitment patterns and isokinetic strength ratios of the shoulder rotator muscles in individuals with and without impingement syndrome. Journal of Shoulder and Elbow Surgery, 17 (2008), 48-53.

[13]A.B. Oliveira, T.O. Sato, L.C. Paschoarelli, H.J.C. Gil Coury Posturas do ombro durante exame ultra-sonográfico utilizando diferentes transdutores, Revista Brasileira de Fisioterapia, 9 (2005), 63-69.

[14]A.G. Orfale, P.M.P. Araújo, M.B. Ferraz, Natour J. Translation into brazilian portuguese, cultural adaptation and evaluation of the reliability of the disabilities of the arm, shoulder and hand questionnaire, Brazilian Journal of Medical and Biological Research, 38 (2005), 293-302.

[15] M.P. Johnson, P.W. Mcclure and A.R. Karduna. New method to assess scapular upward rotation in subjects with shoulder pathology, Journal of Orthopaedic and Sports Physical Therapy, 31 (2001), 81-9.

[16] Sahrmann SA. Diagnóstico e tratamento das síndromes de disfunção dos movimentos. São Paulo: Editora Santos; 2005.

[17] S. De Wolf, H. Slijper and M.L. Latash. Anticipatory postural adjustments during self-paced and reaction-time movements. Exp Brain Res, 121(1998), 7-19.

[18]A. Danna-Dos-Santos, E.Y. Shapkova, A.L. Shapkova, A.M. Degani and M.L. Latash Postural control during upper body locomotor-like movements: similar synergies based on dissimilar muscle modes, Exp Brain Res, 193 (2009), 565-79.

[19] A.S. Aruin, The effect of changes in the body configuration on anticipatory postural adjustments, Motor Control, 7 (2003), 264-77.

[20] V. Krishnamoorthy, M.L. Latash, J.P. Scholz and V.M. Zatsiorsky, Muscle synergies during shifts of the center of pressure by standing persons, Exp Brain Res, 152 (2003), 281-292. Erratum: Exp Brain Res, 155 (2004), 134.

[21]S.K. Varadhan, V.M. Zatsiorsky and M.L. Latash, Variance components in discrete force production tasks, Exp Brain Res, 205 (2010), 335-49.

[22] M. Klous, P. Mikulic, M.L. Latash. Two aspects of feedforward postural control: anticipatory postural adjustments and 
anticipatory synergy adjustments. J Neurophysiol, 105 (2001), 2275-88.

[23]K. Findikcioglu, F. Findikcioglu, S. Ozmen, T. Guclu, The impact of breast size on the vertebral column: a radiologic study, Aesthetic Plastic Surgery, 31 (2007), 23-27 